\title{
Compósito para fabricação de implantes reabsorvíveis para osteossíntese: avaliação da biocompatibilidade em coelhos
}

\author{
Composite for the fabrication of resorbable implants for osteosynthesis: biocompatibility evaluation in rabbits
}

\author{
Emily Correna Carlo ${ }^{I}$ Andrea Pacheco Batista Borges ${ }^{I}$ Luiz Gonzaga Pompermayer ${ }^{I}$ \\ Mastoby Minguel Martinez Martinez ${ }^{\mathrm{II}}$ Renato Barros Eleotério ${ }^{\mathrm{I}}$ Renata Castro Nehme $^{\mathrm{I}}$ \\ Gláucia Oliveira Morato ${ }^{\mathrm{I}}$
}

\section{RESUMO}

A biocompatibilidade, a osseointegração e a reabsorção de compósitos contendo $10 \%$ de hidroxiapatita (HAP-91 ${ }^{\circledR}$ e $90 \%$ de polihidroxibutirato foram analisadas após implantação em defeitos ósseos em coelhos. Foram obtidos dados clínicos, radiográficos, histológicos e histomorfométricos aos oito, 45 e 90 dias após a realização da cirurgia, sendo os resultados comparados aos de defeitos não-preenchidos. Não foram observadas diferenças significativas entre os grupos para os parâmetros clínicos avaliados. Radiografias demonstraram o compósito em contato direto com osso aos 45 e 90 dias. Tecido ósseo se formou normalmente no defeito e na interface com o material, quando comparado ao controle. Não foi observado infiltrado inflamatório. Em todos os dias, a porcentagem de tecido ósseo foi maior que a de tecido conjuntivo ( $P=0,001$ aos 8 e 45 dias e 0,022 aos 90 dias) dentro dos defeitos. Foram observados tecidos ósseo e conjuntivo na interface com o compósito, sendo o último significativamente maior que o primeiro aos 90 dias $(P=0,004)$. Foram observados sinais de reabsorção do compósito: células gigantes na superfície de fragmentos do compósito separados do bloco original. Portanto, pode-se concluir que o compósito é biocompatível em coelhos, reabsorvível e se integra ao tecido ósseo.

Palavras-chave: biomateriais, implantes reabsorvíveis, fraturas ósseas, hidroxiapatita, polihidroxibutirato.

\section{ABSTRACT}
Biocompatibility, osseointegration, and resorption of a $\quad 10 \%$ hydroxyapatite $\left(H A P-91^{\circledR}\right) \quad-\quad 90 \%$

polyhydroxybutyrate composite were analyzed after implantation in rabbits' bone defects. Clinical, radiographic, histologic and histomorphometric data were collected on the $8^{\text {th }}, 45^{\text {th }}$, and $90^{\text {th }}$ days after surgery and the results were compared to those of unfilled defects. No significant differences between groups for the evaluated clinical parameters existed. Radiographs showed bone-composite direct contact. Bone tissue was formed normally in the defect and at the compositetissue interface when compared to the control. No inflammatory infiltrated was observed. For each sampling day, the percentages of bone were greater than those of connective tissues $\left(P=0.001\right.$ on the $8^{\text {th }}$ and $45^{\text {th }}$ days and 0.022 on the $90^{\text {th }}$ day) inside the defect. Bone and connective tissues were seen at the interface with the composite, being the last one significantly greater than the first on the $90^{\text {th }}$ day $(P=0.004)$. Composite's resorption signs were evident: giant cells on the surface of composite fragments separated from the original bloc. Data support that such composite is biocompatible in rabbits, resorbable and integrate to bone.

Key words: biomaterials, resorbable implants, bone fractures, hydroxyapatite, polyhydroxybutyrate.

\section{INTRODUÇÃO}

Atualmente, os implantes ortopédicos mais utilizados para estabilização de fraturas são placas e parafusos fabricados a partir de ligas metálicas, tais como as de titânio e aço inoxidável. A vantagem desses materiais é a grande resistência às diversas forças exercidas sobre eles. Contudo, esses materiais apresentam desvantagens, tais como propriedades

IDepartamento de Veterinária, Universidade Federal de Viçosa (UFV). Av. P.H. Rolfs, s/n, 36570-000, Viçosa, MG, Brasil. Tel.: (31) 9204-8050. Fax: 3899-2317. E-mail: emilycarlo@yahoo.com.br. Autor para correspondência.

IUniversidade de Córdoba, Córdoba, Colômbia. 
mecânicas muito diferentes das do osso, que podem afetar a consolidação e a remodelação ósseas e a liberação de detritos citotóxicos responsáveis por hipersensibilidades, respostas inflamatórias contínuas e até mesmo neoplasias (ITO et al., 2005; RASSE et al., 2007).

No mercado internacional, existem implantes ortopédicos biodegradáveis fabricados por diferentes processamentos e proporções de ácido poliláctico e ácido poliglicólico. Além disso, também há estudos relativos à implantação desses implantes. No entanto, podem ser citadas limitações como alto custo e baixa resistência mecânica, além de não permitir osteointegração e de existirem relatos de inflamação asséptica e osteólise associadas aos debris produzidos durante a degradação, (AN et al., 2000; RASSE et al., 2007).

Este estudo investigou a resposta ao compósito associando a hidroxiapatita sintética HAP$91^{\circledR}$ ao polihidroxibutirato (PHB) desenvolvido com matérias-primas e tecnologia nacionais (OLIVEIRA, 2005) quando implantado em defeitos ósseos em coelhos, analisando características de biocompatibilidade, reabsorção e osseointegração. A HAP-91 ${ }^{\circledR}$, semelhante ao principal constituinte mineral do tecido ósseo, é bioativa, porém, friável. As características mecânicas do PHB são compatíveis com as do osso, mas este não é bioativo, importante para osteointegração. A associação desses biomateriais visou unir a bioatividade da hidroxiapatita às características mecânicas do PHB (BORGES et al., 2000; CHENG et al., 2006).

\section{MATERIAL E MÉTODOS}

Foram utilizados 24 coelhos da raça Nova Zelândia, pesando entre 3 e 3,5kg. Os animais estavam alojados em gaiolas individuais e recebiam dose única de ivermectina $\left(0,4 \mathrm{mg} \mathrm{kg}^{-1}\right)$ por via intramuscular (IM) no dia de chegada, ou seja, 60 dias antes da realização das cirurgias. Eles receberam ração duas vezes ao dia e água ad libitum e foram separados aleatoriamente em dois grupos com igual número de animais, os grupos controle e teste.

Os animais receberam penicilina $\mathrm{G}$ (40.000UI $\mathrm{kg}^{-1}$, IM) trinta minutos antes da cirurgia, foram sedados com levomepromazina (2mg kg-1, IM) e anestesiados com associação de tiletamina-zolazepam (15 $\mathrm{mg} \mathrm{kg}^{-1}$ de cada substância, IM). A região da diáfise do úmero até o carpo foi tricotomizada e foi realizado bloqueio anestésico do plexo braquial com 1,5ml de lidocaína a $2 \%$ após a anti-sepsia com povidine tópico.
Foi realizada incisão de pele na superfície lateral da articulação úmero-rádio-ulnar e o músculo tríceps braquial foi afastado, expondo a superfície lateral do olécrano. Foi confeccionada uma falha óssea circular de $4 \mathrm{~mm}$ de diâmetro na cortical lateral do olécrano, com o auxílio de uma broca trefina acoplada a uma perfuratriz elétrica sob irrigação com solução fisiológica estéril.

Os compósitos com 10\% de hidroxiapatita sintética (HAP $91^{\circledR}$ - JHS Laboratório Químico LTDA) e $90 \%$ de PHB, fornecidos com um formato retangular, foram cortados com a mesma broca trefina usada na confecção do defeito (4mm de diâmetro) para adequar o tamanho e o formato dos compósitos ao defeito. Os animais do grupo teste receberam o compósito dentro do defeito e os do grupo controle não tiveram os defeitos preenchidos. Os tecidos foram aproximados com fio de náilon.

No pós-operatório imediato, foram realizadas radiografias nas posições mediolateral com a articulação úmero-rádio-ulnar. A medicação pósoperatória consistiu de morfina ( $2 \mathrm{mg} \mathrm{kg}^{-1}$, IM) em dose única ou a cada seis horas, de acordo com o exame clínico, e a penicilina (40.000UI $\mathrm{kg}^{-1}$ ) a cada 24 horas por dois dias.

Diariamente, nos primeiros oito dias e após 45 e 90 dias, foram realizadas avaliações clínicas a partir dos seguintes parâmetros: a) claudicação, de acordo com o apoio da extremidade do membro com os escores: 0 - sem claudicação, 1 - apoio com claudicação e 2 - ausência completa de apoio; b) presença ou ausência de infecção da ferida cirúrgica e deiscência; c) reação inflamatória, avaliando o edema quantitativamente pela mensuração da circunferência do membro no local da ferida cirúrgica e d) sensibilidade dolorosa, avaliada pela reação do animal ao toque da ferida cirúrgica e flexão e extensão da articulação úmero-rádio-ulnar, atribuindo-se os escores: 0 - quando não existiu manifestação do animal, 1 - retração do membro sem outra manifestação e 2 retração do membro associada à vocalização ou à tentativa de fuga.

A avaliação estatística para as variáveis infecção, claudicação, dor e deiscência consistiu na comparação entre os dias um, quatro e oito dentro de cada grupo e na comparação entre os grupos utilizandose, respectivamente, os testes estatísticos de KruskalWallis e Mann-Whitney. A variável edema foi avaliada com teste de Wilcoxon. As médias das diferenças de circunferência foram comparadas entre os grupos com teste de Kruskal-Wallis. Em toda a análise estatística realizada no presente trabalho, o valor de P menor que 0,05 foi considerado significante. 
Nos dias oito, 45 e 90, foram realizadas duas radiografias de quatro animais de cada grupo na posição mediolateral. Esquemas em folhas de transparência foram confeccionados com círculos do exato tamanho dos defeitos, divididos em quatro quadrantes. Os esquemas sobrepostos às radiografias resultaram em defeitos com quatro quadrantes, avaliando-se separadamente a radiopacidade de cada um deles, caracterizada em menor, semelhante ou maior que a do osso vizinho. Foram observadas também as bordas do defeito/compósito, caracterizando se o limite entre o osso e o compósito podia ser bem estabelecido.

Quatro animais de cada grupo foram submetidos à eutanásia com sobredose anestésica em cada um dos dias oito, 45 e 90 após a cirurgia quando foram coletadas amostras do olécrano contendo o defeito. As amostras foram fixadas em formol $10 \%$ tamponado por três dias, descalcificadas em ácido fórmico a $10 \%$ tamponado com citrato de sódio para pH 4,5 sob vácuo moderado por 20 dias. Em seguida, as amostras foram seccionadas no sentido transversal ao eixo longo da ulna, no centro do defeito, para se obter a superfície de análise. Posteriormente elas foram lavadas em água corrente e então desidratadas, diafanizadas e incluídas em parafina (Laboratório de Patologia, DVT-UFV). Foram obtidos cortes de cinco ìm de espessura, que foram corados com azul de toluidina (AT) para análise à microscopia de luz.

Em análise qualitativa, foram caracterizados os tecidos e as células presentes em toda a amostra. À histomorfometria, o número de osteoclastos presentes em 10 campos por amostra foi contado em aumento de 200X em ambos os grupos. Utilizando o teste estatístico de Kruskal-Wallis seguido pelo teste de Dunn's, analisou-se a diferença entre os dias e MannWhitney para a diferença entre os grupos. Para analisar a formação do tecido ósseo na presença do compósito, foram quantificados percentualmente o compósito, o tecido ósseo, o tecido conjuntivo e a medula óssea presentes no interior do defeito com auxílio de ocular graduada em aumentos de 40X somente no grupo teste, utilizando para comparação apenas os tecidos ósseo e conjuntivo. Para analisar qual tecido predominou apenas na interface com o compósito, realizou-se a caracterização dos tecidos presentes na interface com uma ocular graduada em aumentos de 200X. Para tanto, foram considerados apenas os primeiros pontos de interseção imediatamente após o compósito em cada linha, permitindo a obtenção do percentual de tecido ósseo, medula óssea e tecido conjuntivo. A porcentagem média dos tecidos ósseo e conjuntivo presentes no defeito e na interface foram comparadas pelo teste de Mann-Whitney.

\section{RESULTADOS E DISCUSSÃO}

Em quatro animais (três controles e um teste) houve necessidade de administrar outras duas doses de morfina durante o primeiro dia do pósoperatório, pois os pacientes demonstraram sinais clínicos de dor e claudicação. A partir dessas observações e considerando a natureza do procedimento ortopédico realizado, estudos futuros dessa natureza na espécie envolvida deverão ser acompanhados de rígido controle analgésico.

Em duas amostras (45 e 90 dias), o compósito se separou do tecido adjacente no momento da microtomia, fato que pode ser explicado a partir de observações semelhantes de DOYLE et al. (1991) e LUKLINSKA \& BONFIELD (1997). À microscopia eletrônica de transmissão e varredura, esses últimos autores observaram uma matriz de PHB em degradação na interface, responsável pela fratura e separação, atribuindo o problema ao início da reabsorção do material e não à quebra do implante. Essa hipótese foi confirmada à histologia como descrito a seguir. Além disso, após a descalcificação, o material ainda era rígido, o que dificultou a microtomia, permitindo a atuação das forças de arrasto desse procedimento no PHB em degradação (DOYLE et al., 1991). A contração dos tecidos durante o processamento histológico (DENISSEN \& GROOT, 1990) também pode ter atuado no PHB em degradação na interface, contribuindo para a separação.

Dor e claudicação foram observadas no primeiro dia após a cirurgia, ambas classificadas em grau 1. Foram observadas deiscência e infecção sem diferenças significativas entre os grupos. Houve diferença significativa entre os valores préoperatórios da circunferência do membro em relação aos valores do primeiro e quarto dias, com valores de P iguais a 0,01 e 0,039 no grupo controle e 0,002 e 0,039 no grupo teste, respectivamente, indicando a existência de aumento de volume em ambos os grupos. Não existiram diferenças significativas entre os valores do pós-operatório imediato e os dias oito, 45 e 90, assim como entre as médias das diferenças de circunferência dos membros entre os grupos. Esses dados sugerem que o compósito seja biocompatível e que a existência desses sinais se deveu à manipulação cirúrgica e não à presença do biomaterial (BORGES et al., 2000).

Os defeitos no controle apresentaram radiopacidade menor que a do osso vizinho em todos os quadrantes no pós-operatório imediato e aos oito dias, com bordas bem delimitadas evoluindo para radiopacidade semelhante à do osso próximo ao defeito em 58,3\% dos quadrantes aos 90 dias. Apesar de o 
compósito apresentar radiopacidade inferior à do osso, era facilmente identificado a partir da observação de um halo menos radiopaco ao seu redor, nas radiografias do pós-operatório imediato e aos oito dias, correspondendo à distância entre a parede do defeito e o compósito. Esse halo foi resultado da utilização da mesma broca para fazer o defeito no osso e o corte do compósito, retirando do osso o diâmetro externo da broca e deixando o compósito com o diâmetro interno da mesma. Os tecidos presentes nesse halo menos radiopaco correspondiam ao coágulo imediatamente após a cirurgia e provavelmente aos tecidos moles, conjuntivo ou osso imaturo, aos oito dias, que participam da regeneração do tecido ósseo (BORGES et al., 2000). Nesses mesmos dias, as bordas foram bem delimitadas em todos os quadrantes. Aos 45 e 90 dias, não era possível delimitar 37,5 e 31,25\% das margens dos quadrantes, respectivamente, onde não mais existia o halo menos radiopaco que o osso próximo ao defeito e os defeitos diminuíram de tamanho. Portanto, foi constatada a neoformação óssea nas bordas do compósito, reforçando a biocompatibilidade e indicando a osseointegração (DOYLE et al., 1991; KNOWLES et al., 1992; LUKLINSKA \& BONFIELD, 1997).

A biocompatibilidade do compósito também foi confirmada pela histologia, já que em nenhuma das amostras foi observado infiltrado inflamatório, o que está de acordo com resultados de CHENG et al. (2006) e SHISHATSKAYA et al. (2006).

Nas amostras do grupo controle, observouse o processo normal de reparação óssea com numerosas trabéculas novas partindo da região medial ao defeito, com grande número de osteoblastos ativos e osteoclastos em suas margens, entremeadas por tecido conjuntivo denso vascularizado. Aos 45 dias o tecido ósseo apresentou-se mais organizado e aos 90 dias a cortical lateral do ólecrano estava restabelecida, com tecido ósseo trabecular organizado no centro.

Os tecidos observados nos defeitos do grupo teste aos oito dias foram muito semelhantes ao grupo controle, também com intensa formação de tecido ósseo trabecular novo partindo da região medial ao defeito (Figura 1A), entremeado por tecido conjuntivo denso vascularizado, evoluindo aos 45 e 90 dias para um tecido ósseo trabecular mais organizado. À análise histomorfométrica, pode-se notar que em todos os dias o percentual de tecido ósseo formado foi significativamente maior que de tecido conjuntivo (Tabela 1 ), valor de $P$ igual a 0,001 aos 8 e 45 dias e 0,022 aos 90 dias. Portanto, a presença dos compósitos não afetou negativamente o desenvolvimento do tecido ósseo, considerando: a neovascularização, a diferenciação de células osteoprogenitoras, a formação de novo osso e o remodelamento ósseo (BORGES et al., 2000; WALSH et al., 2003). Esses dados poderão embasar novos estudos referentes às características mecânicas in vivo para posterior fabricação de implantes.

Não existiram diferenças significativas no número de osteoclastos entre os grupos. Foram observadas diferenças significativas no número dessas células entre oito e 90 dias dentro de cada grupo (teste: $\mathrm{P}=0,023$ / controle: $\mathrm{P}=0,032$ ). Esses dados reforçam que o compósito não interfere negativamente no desenvolvimento do tecido ósseo, já que os osteoclastos são as células responsáveis pela reabsorção óssea, importante para a formação e a remodelação desse tecido (WALSH et al., 2003).

A interface com o compósito constituiu tanto de tecido ósseo (Figura 1B) como conjuntivo (Figura 1C). Não existiu diferença significativa entre as porcentagens desses tecidos aos oito e 45 dias. $\mathrm{O}$ percentual de tecido conjuntivo foi significativamente maior que o percentual de tecido ósseo aos 90 dias $(\mathrm{P}=0,004)$ (Tabela 1$)$. Esses dados podem ter sido influenciados por diferentes fatores, já que o tecido conjuntivo predominou na interface das regiões distal e proximal ao defeito e o tecido ósseo na região medial. A distância entre a parede óssea do defeito e o compósito pode ter permitido a invasão de tecido conjuntivo, fato que retarda ou até impede a formação do tecido ósseo (MACNEILL et al., 1999). A presença de grande quantidade de medula óssea na região medial ao defeito, origem de células osteoprogenitoras (BROWN \& KRAMERS, 1996), pode ter influenciado a formação de tecido ósseo nessa região, o que não ocorre de forma tão pronunciada nas regiões proximal e distal, local de predominância de osso cortical.

Fragmentos de compósito separados do bloco original em meio ao tecido ósseo adjacente estavam presentes nas bordas proximal, distal e medial ao defeito aos 90 dias, sugerindo a reabsorção do mesmo com separação de fragmentos do bloco original e sua possível e gradual substituição, corroborando os resultados de estudos anteriores (LUKLINSKA \& BONFIELD, 1997; SHISHATSKAYA et al., 2006). Na região lateral ao compósito, os fragmentos estavam em meio a tecido mesenquimal com grande número de células blásticas, que apresentava continuidade com o tecido ósseo adjacente. Células gigantes foram observadas ao redor desses fragmentos e também osteóide, sugerindo a possibilidade de formação de tecido ósseo neste local. Células gigantes são responsáveis pela reabsorção de material e restos 


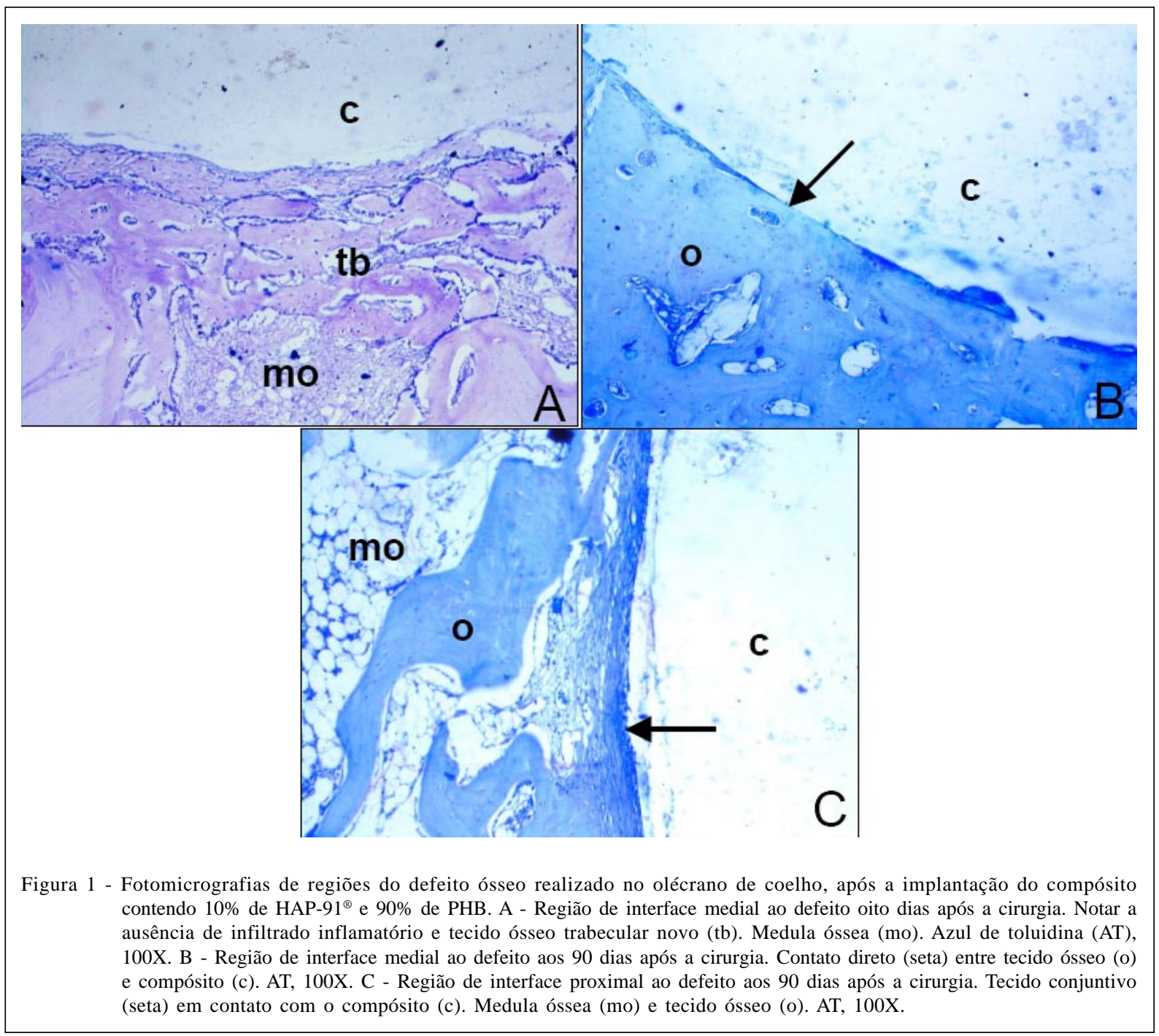

teciduais em locais de reparação, observadas tanto na reabsorção da hidroxiapatita como do PHB separadamente (BORKENHAGEN et al., 1998; BORGES et al., 2000; VOLOVA et al., 2003; SHISHATSKAYA et al., 2005). Desse modo, as características observadas sugerem o processo de reabsorção do compósito. Esse processo, observado aos 90 dias, é de grande importância, visto que um material para osteossíntese não deve ser reabsorvido antes da consolidação óssea, condição já observada em outros materiais reabsorvíveis, tais como o PGA puro (AN et al., 2000).

\section{CONCLUSÕES}

Com base nos resultados obtidos, pode-se concluir que o compósito de HAP- $91^{\circledR}$ associado ao
PHB nas condições descritas é biocompatível, se integra ao tecido ósseo e é reabsorvido in vivo, podendo-se prosseguir com novos estudos para posterior fabricação de implantes reabsorvíveis.

\section{AGRADECIMENTOS}

Os autores agradecem a JHS Laboratório Químico, Sabará - MG, na pessoa da Dra. Sheyla Maria de Castro Máximo Bicalho, pelo apoio e fornecimento do material, e à Coordenação de Aperfeiçoamento de Pessoal de Nível Superior (CAPES), pela bolsa de mestrado de Emily Correna Carlo.

\section{COMITÊ DE ÉTICA E BIOSSEGURANÇA}

A metodologia deste trabalho foi aprovada pela Comissão de Ética do DVT / UFV, em consonância com o estabelecido pelo Colégio Brasileiro de Experimentação Animal (COBEA), aprovada em 01/03/2007 e protocolada como processo no 37 / 2007.

Ciência Rural, v.39, n.1, jan-fev, 2009. 
Tabela 1 - Dados histomorfométricos da região de defeitos experimentais na ulna de coelhos aos oito, 45 e 90 dias após a implantação de compósitos contendo $10 \%$ de HAP- $91^{\circledR}$ e $90 \%$ de PHB. Médias e desvios-padrão das porcentagens de tecido ósseo e tecido conjuntivo formados no interior dos defeitos ósseos e na interface (região de contato entre compósito e tecidos).

\begin{tabular}{|c|c|c|c|c|}
\hline \multirow{2}{*}{ Dia } & \multicolumn{2}{|c|}{-----------------Dentro do defeito----------------- } & \multicolumn{2}{|c|}{-------------------------Interface------------------------ } \\
\hline & Tecido ósseo & Tecido conjuntivo & Tecido ósseo & Tecido conjuntivo \\
\hline 8 & $42,3 \pm 8,3$ a & $13,3 \pm 8,8 b$ & $29,9 \pm 21,6 \mathrm{c}$ & $68,7 \pm 21,6 \mathrm{c}$ \\
\hline 45 & $52,7 \pm 3,6$ a & $0 \mathrm{~b}$ & $57,4 \pm 14,8 \mathrm{c}$ & $24,4 \pm 26,5 \mathrm{c}$ \\
\hline 90 & $38,2 \pm 3,7 \mathrm{a}$ & $0 \mathrm{~b}$ & $18,4 \pm 1,3$ с & $74,3 \pm 2,6 \mathrm{~d}$ \\
\hline
\end{tabular}

Letras diferentes na mesma linha dentro de cada análise sinalizam diferença significativa pelo teste de Mann-Whitney, P<0,05.

\section{REFERÊNCIAS}

AN, H.Y. et al. Pre-clinical in vivo evaluation of orthopaedic bioabsorbable devices. Biomaterials, v.21, n.24, p.26352652, 2000

BORGES, A.P.B. et al. Hidroxiapatita sintética como substituto ósseo em defeito experimental provocado no proximal da tíbia de cão: aspectos à microscopia de transmissão. Arquivo Brasileiro de Medicina Veterinária e Zootecnia, v.52, n.6, p.616-620, 2000.

BORKENHAGEN, M. et al. In vivo performance of a new bidegradable polyester urethane system used as a nerve guidance channel. Biomaterials, v.19, n.23, p.2155-2165, 1998.

BROWN, S.G.; KRAMERS, P.C. Consolidação óssea indireta (secundária). In: ______. Mecanismos da moléstia na cirurgia de pequenos animais. São Paulo: Manole, 1996. p.783-790.

CHENG, S. et al. The effect of d,l-2?hydroxybutyric acid on cell death and proliferation in L929 cells. Biomaterials, v.27, n. 20, p.3758-3765, 2006.

DENISSEN, H.W.; GROOT, K. Immediate dental root implants from synthetic dense calcium hydroxyapatite. Journal of Prosthetic Dentistry, v.42, n.5 p.551-555, 1990.

DOYLE, C. et al. In vitro and in vivo evaluation of polyhydroxybutyrate and of polyhydroxybutyrate reinforced with hydroxyapatite. Biomaterials, v.12, n.9, p.841-847, 1991.

ITO, Y. et al. A composite of hydroxyapatite with electrospun biodegradable nanofibers as a tissue engineering material.
Journal of Bioscience and Bioengineering, v.100, n.1, p.43-49, 2005.

KNOWLES, J.C. et al. Development of a degradable composite for orthopaedic use: in vivo biomechanical of two bioactive degradable composites based on the polyhydroxybutyrate polymer. Biomaterials, v.13, n.8, p.491-496, 1992.

LUKLINSKA, Z.B.; BONFIELD, W. Morphology and ultrastructure of the interface between hydroxyapatitepolyhydroxybutyrate composite implant and bone. Journal of Material Science: Materials in Medicine, v.8, n.6, p.379-383, 1997.

MACNEILL, S.R. et al. In vivo comparison of synthetic osseous graft materials. A preliminary study. Journal of Clinical Periodontology, v.26, n.4, p.239-245, 1999.

OLIVEIRA, P.M. Desenvolvimento e caracterização de compósitos de matriz polimérica de $\mathrm{PHB}$ reforçados com HAP-91 ${ }^{\circledR}$. 2005. 148f. Dissertação (Mestrado em Engenharia de Materiais) - Curso de Pós-graduação em Engenharia de Materiais, Universidade Federal de Ouro Preto.

RASSE, M. et al. Resorbable poly(D, L)lactide plates and screws for osteosynthesis of condylar neck fractures in sheep. British Journal of Oral and Maxillofacial Surgery, v.45, n.1, p.35-40, 2007.

SHISHATSKAYA, E.I. et al. Degradation of $\mathrm{P}(3 \mathrm{HB})$ and $\mathrm{P}(3 \mathrm{HB}-\mathrm{co}-3 \mathrm{HV})$ in biological media. Journal of Biomaterial Science Polymer Edition, v.16, n.5, p.643657, 2005. 